Daniel L. Waters

\title{
Case Study: The advancement of energy and carbon management at Gosford City Council.
}

\author{
Mr. Daniel L. Waters \\ Carbon \& Energy Management Officer \\ Gosford City Council \\ 49 Mann Street Gosford NSW \\ dan.waters@gosford.nsw.gov.au
}

DOI: http://dx.doi.org/10.5130/ssep2016.525

\begin{abstract}
There are various approaches to energy and carbon management and the most appropriate approach is likely to change over time. Selecting the appropriate approach is pivotal in determining how successful an organisation will be in achieving its energy and carbon management objectives. Over the last fifteen years, Gosford City Council has undergone numerous shifts in its approach to the management of energy and carbon across its operations.

Council initially focused on reducing its carbon footprint, firstly by setting aspirational targets and followed by the setting of evidence based targets. In response to rising energy costs, Council shifted from a "carbon abatement" to an "energy management" focus in 2012. At this time, the sophistication of Council's energy management program was vastly improved with the introduction of a corporate energy management information system and a revolving energy fund. In 2014, Council's energy management program focused on "use less" and "pay less" levers. The first lever "use less" covered much the same ground as previous carbon abatement approaches, however, the second energy management lever, "pay less" unlocked significant additional value to Council. Payless initiatives, such as energy procurement, load shifting, energy account management and bill validation resulted in energy cost savings of hundreds of thousands of dollars for Council.
\end{abstract}

Council is now shifting from a tactical to a more strategic approach to energy management. An Energy Management Strategy is under development. The Energy Management Strategy will introduce an Energy Productivity Improvement Objective. This objective will focus on recognising the complete economic value of improved energy and carbon management. This should yield organisational productivity improvements and economic value in the local community. The strategy also introduces advanced energy metrics such as an energy cost index and asset class energy intensity metrics.

The appropriate approach for Gosford City Council's energy and carbon management has advanced in line with wider organisation objectives, values and maturity of its energy management systems.

\section{Introduction}

Over the last fifteen years Gosford City Council has achieved several milestones in its approach to energy and carbon management. Whilst Council has undertaken community carbon abatement initiatives through its plans and education programs, this paper focuses on Gosford City Council's approach to carbon and energy management from its own operations. The paper will cover key energy and carbon milestones, outline Council's carbon footprint, discuss the advancement of Council's carbon and energy management and how the concept of energy productivity is guiding the current strategy under development.

\section{Energy \& Carbon Management Milestones}

There have been five key milestones associated with the advancement of Council's carbon and energy management since 1999. Each milestone continues to build on the achievements of the previous milestone. The Cities for Climate Protection Program was designed to improve carbon management. The climate change policy formalised Council's commitment and integrated carbon management with climate change adaption risks. The Climate Change Mitigation Strategy provided more information and evidence to support cost effective carbon abatement. The introduction of a revolving energy fund was designed to address the capital funding project 
implementation barrier. The carbon \& energy management system improved the carbon and energy performance of Council. The energy management strategy currently under development introduces energy productivity as an additional benefit. The following timeline shows a shift from a carbon abatement focus to an energy management focus (Table 1).

Table 1 Energy \& Carbon Management Timeline

\begin{tabular}{|c|c|c|c|c|c|}
\hline 1999-2009 & 2010 & 2011-2012 & 2012 & 2012-2014 & 2015 \\
\hline Cities for & Climate & Climate Change & Revolving & Carbon \& Energy & Energy \\
\hline Climate & Change Policy & Mitigation & Energy Fund & Management & Management \\
\hline Protection & & Strategy & & $\begin{array}{l}\text { System } \\
\text { Improvements }\end{array}$ & Strategy \\
\hline
\end{tabular}

\section{Cities for Climate Protection (1999-2009)}

The Cities for Climate Protection (CCP) program was an initiative of the International Council for Local Environmental Initiatives (ICLEI). Gosford City Council joined the CCP program in 1999. The CCP program involved five steps:

1. Inventory and Forecast

2. Setting a Reduction Goal

3. Developing a Local Action Plan

4. Implementation

5. Monitoring and Reporting

Council set two aspirational voluntary targets under the Cites for Climate Protection program:

$50 \%$ reduction in per capita carbon emissions from Council operations by 2020, based on 2001 levels.

$50 \%$ renewable energy by 2020.

The CCP was an important step in raising the profile and need for carbon abatement. The CCP was successful in gaining support at the political level and adopting aspirational targets. The main shortfall of the CCP was the lack of management buy-in and integration into corporate planning. This may have been a function of the bureaucratic structure with the responsibility of climate change sitting with the environment section and not seen as a responsibility of other sections of Council. There were also energy and carbon data quality and completeness issues. The information systems were insufficient to collect adequate data on energy consumption and carbon emissions. These barriers combined to result in an unwillingness to invest the resources into climate change mitigation strategies. Consequently the targets were treated as long term aspirational targets and failed to drive any significant change to the emissions from Council operations.

\section{Climate Change Policy (2010)}

Increasing regulatory reporting requirements and rising energy cost triggered senior management to renew efforts to improve energy and carbon management. This included the creation of a dedicated full time position and the development and adoption of a climate change policy in 2010. The policy provided a strategic framework for managing both climate change mitigation and adaptation risks. It included a high level hierarchy for removing the sources of carbon emissions and increasing carbon sinks (Figure 1). The policy formalised Council's commitment and provided a framework for Council's Climate Change Mitigation Strategy. 


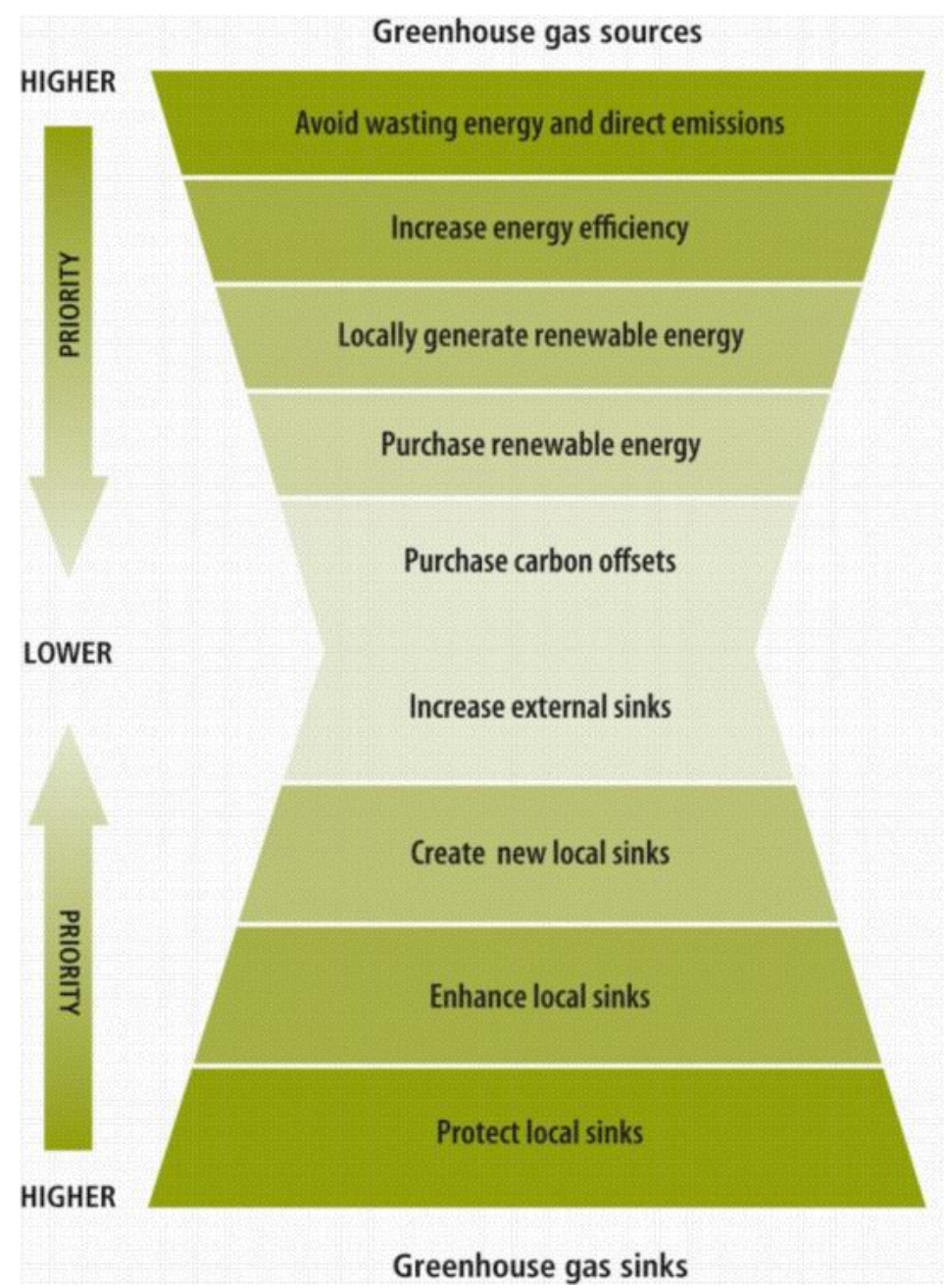

Figure 1 Climate change policy abatement hierarchy

\section{Climate Change Mitigation Strategy (2012)}

The overarching purpose of the Climate Change Mitigation Strategy (CCMS) project was to develop a sustainable climate change mitigation strategy for Council operations and the community, in alignment with Council's key policies and plans (Dowling et al, 2012). The key drivers behind the need for an updated carbon reduction strategy were lack of ownership and implementation of the existing CCP strategy, increasing energy costs and new technologies. The objective of the strategy was: "To reduce Gosford City Council's carbon footprint, and assist the community to reduce their footprint, in an achievable and sustainable manner" (Dowling et al, 2012).

The climate change mitigation strategy utilised a bottom up evidence based approach for setting the reduction target. It established an emissions baseline by calculating Council's carbon footprint, including a business as usual emissions forecast. It improved Council's understanding of the carbon abatement potential by identifying and evaluating carbon abatement opportunities based on a triple bottom line lifecycle costing approach.

The CCMS methodology combined robust data analysis with stakeholder engagement at each of the four development stages:

1) Project inception and ob jective setting

2) Development of carbon footprint inventory for GCC

3) Identification and assess ment of carbon abatement opportunities

4) Development of strateg ic scenarios

The use of stakeholder engagement and robust data analysis in the methodology assisted with addressing the implementation barriers of the Cities for Climate Protection Program (i.e. lack of buy-in and perceived lack of robust evidence). 
The strategy target was based on a selection of abatement opportunities comprising energy efficiency, renewable energy, carbon emissions capture and destruction, community abatement programs and demand management opportunities. The abatement opportunities identified in the marginal abatement cost curve were used to guide the level of abatement to be targeted by the strategy (Figure 2). Council adopted a carbon reduction target of $20 \%$ at 2025 based on 2010 levels.

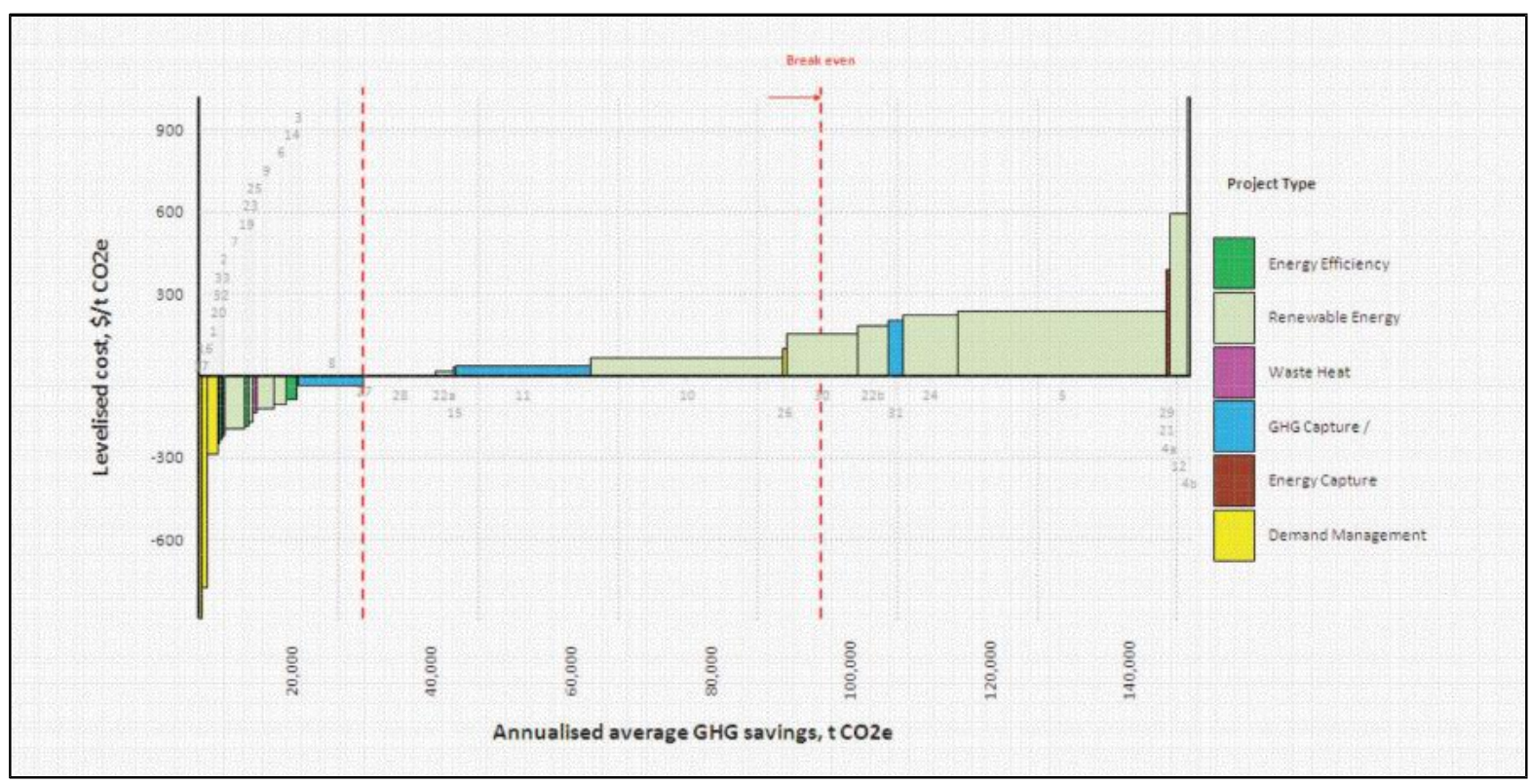

Figure 2 Gosford City Council Carbon Abatement Marginal Cost Curve

Since adopting the carbon reduction target, the emissions from landfills and wastewater treatment plants have been most variable with significant increases and reductions from year to year (Figure 3). The decomposition of waste in landfills creates carbon emissions. Council has a landfill gas extraction system at its landfills which capture the landfill gas more than halving the landfills' carbon footprint. The captured landfill gas is used to fuel engines which generate enough electricity to power over 2050 local homes.

Carbon emissions from electricity use have remained relatively stable with growth and energy efficiency improvements balancing each other out. The emissions from transport fuels have dropped by $10 \%$ over the last year primarily from reductions in usage and efficiency improvements (Figure 3). The continued implementation of the Climate Change Mitigation Strategy the carbon gas reduction target is achievable. The 2015 carbon inventory highlights the importance further reducing landfill, wastewater treatment and electricity emissions. Council is on track to meeting the target by 2025 with major projects underway such as the roll out of over 1,600 solar photovoltaic panels, landfill gas capture and other energy efficiency improvements. 


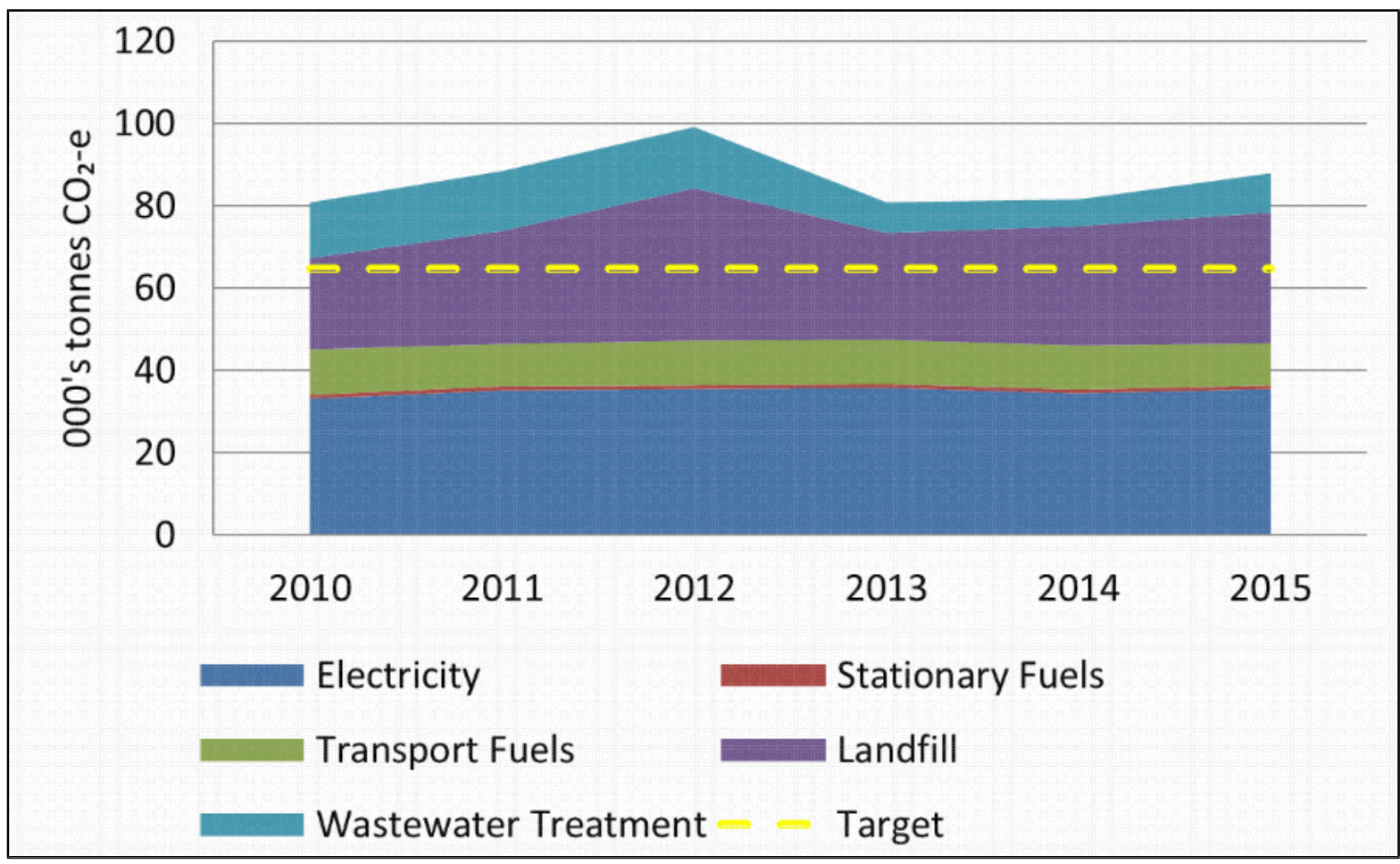

Figure 3 Gosford City Council Carbon footprint (000's t CO2-e)

\section{Revolving Energy Fund}

The revolving energy fund is designed to be a financially sustainable source of capital to fund cost effective energy and carbon projects. Energy cost savings from energy projects and other energy management initiatives were identified to be captured by the revolving energy fund. For example, the revolving energy fund recently invested in a project that installed 1,600 solar panels $(434 \mathrm{~kW})$ on Council facilities with an internal rate of return over $10 \%$.

\section{Carbon \& Energy Management System Improvements (2012-2014)}

The development of the Climate Change Mitigation Strategy highlighted the need to further improve carbon and energy management systems. The sophistication of Council's carbon and energy management program was vastly improved following the introduction of an organisational carbon and energy management information system in 2012. The information system provided carbon, energy and cost data.

Improvements to Council's energy management systems have led to improved energy consumption and cost performance. Reliable and timely energy and carbon data is necessary for the design, implementation and measurement of system improvements. The improved energy information system allowed the identification and verification of ways to reduce Council's energy consumption, such as avoiding unnecessary energy use, improving energy efficiency and generating energy on site. It also gave Council the data to identify ways to pay less for energy.

Traditionally there have been three broad reduction objectives for Council's carbon and energy management activities; carbon footprint, energy cost and energy consumption. Each of the three objectives can be thought of as a different lens through which to view Council's operations. Each lens highlights a different asset class as the most important in terms of their relative contribution (Figure 4). For example, the landfills are the largest source of carbon emissions, but have very little energy use and energy cost. If the primary objective is to reduce Council's carbon footprint, the landfills, wastewater treatment and pumping would be the asset classes to focus attention on. Energy cost and consumption are more closely aligned with some exceptions due to relative differences in the unit cost of energy sources. For example, transport is the largest asset class in terms of energy consumption, whereas wastewater pumping and treatment has the largest energy costs. This is because the unit cost of energy from liquid fuels $(\$ 31.9 / \mathrm{GJ})$ is $35 \%$ less than the unit cost of electricity $(\$ 49.3 / \mathrm{GJ})$. 


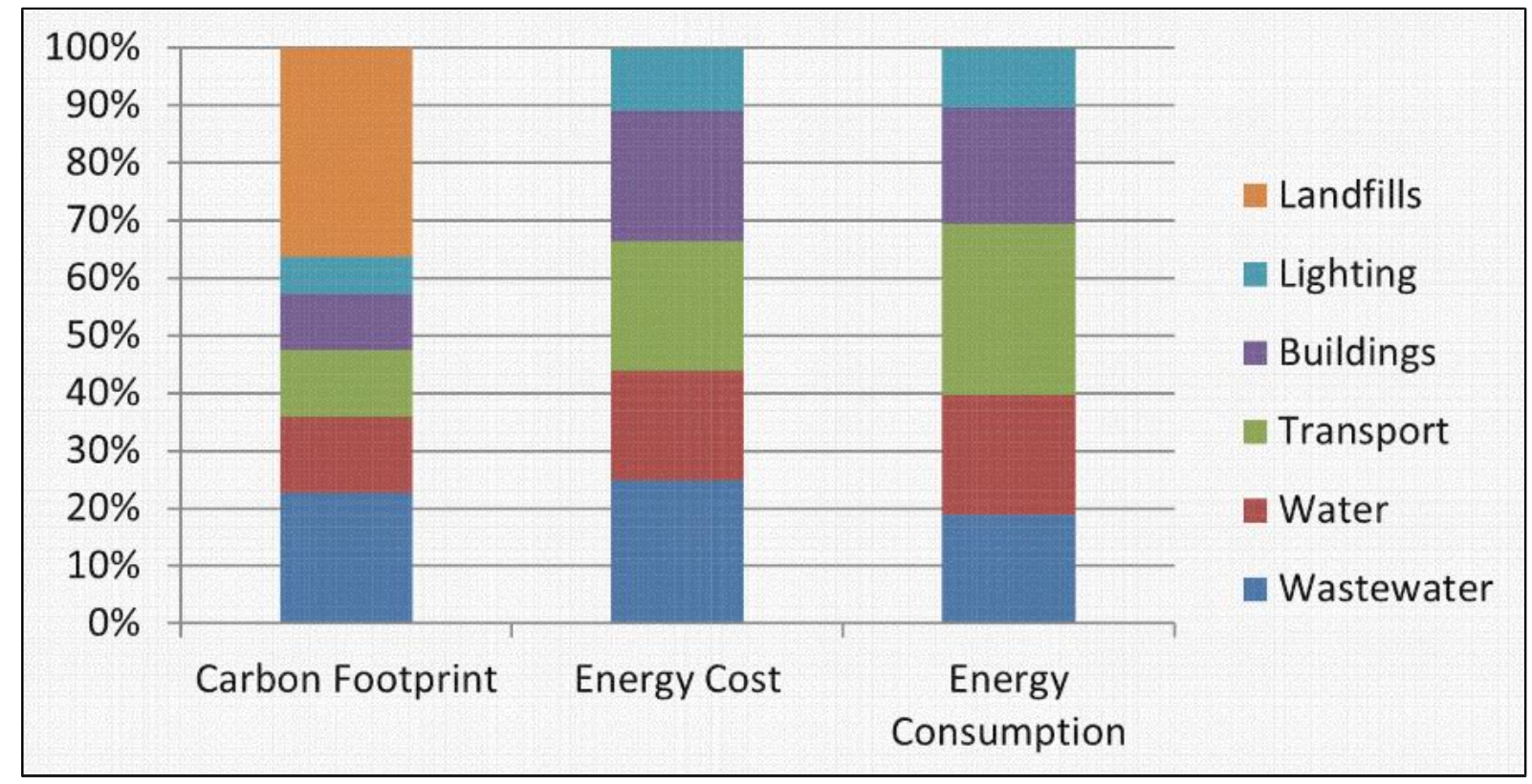

Figure 4 Council 20145/15 carbon footprint, energy cost and consumption by asset class

In the four years to 2013, Council's energy cost increased by $61 \%$ (Figure 5). This dramatic increase was not due to increased energy consumption which remained steady (Figure 6), but was almost entirely due to increased electricity prices. In response, Council expanded its "pay less" energy management initiatives. Energy cost savings over $\$ 822,000$ were achieved by initiatives such as improved electricity procurement practices, bill validation, load shifting, electricity account management and tariff optimisation. The cost of transport fuels also dropped by $24 \%$ compared to last year driven primarily by reductions in usage and price. These improvements along with external factors such the repeal of the Clean Energy Act 2011 have reduced Council's annual energy cost by $\$ 2.2 \mathrm{M}$ from its peak in 2013 (Figure 5).

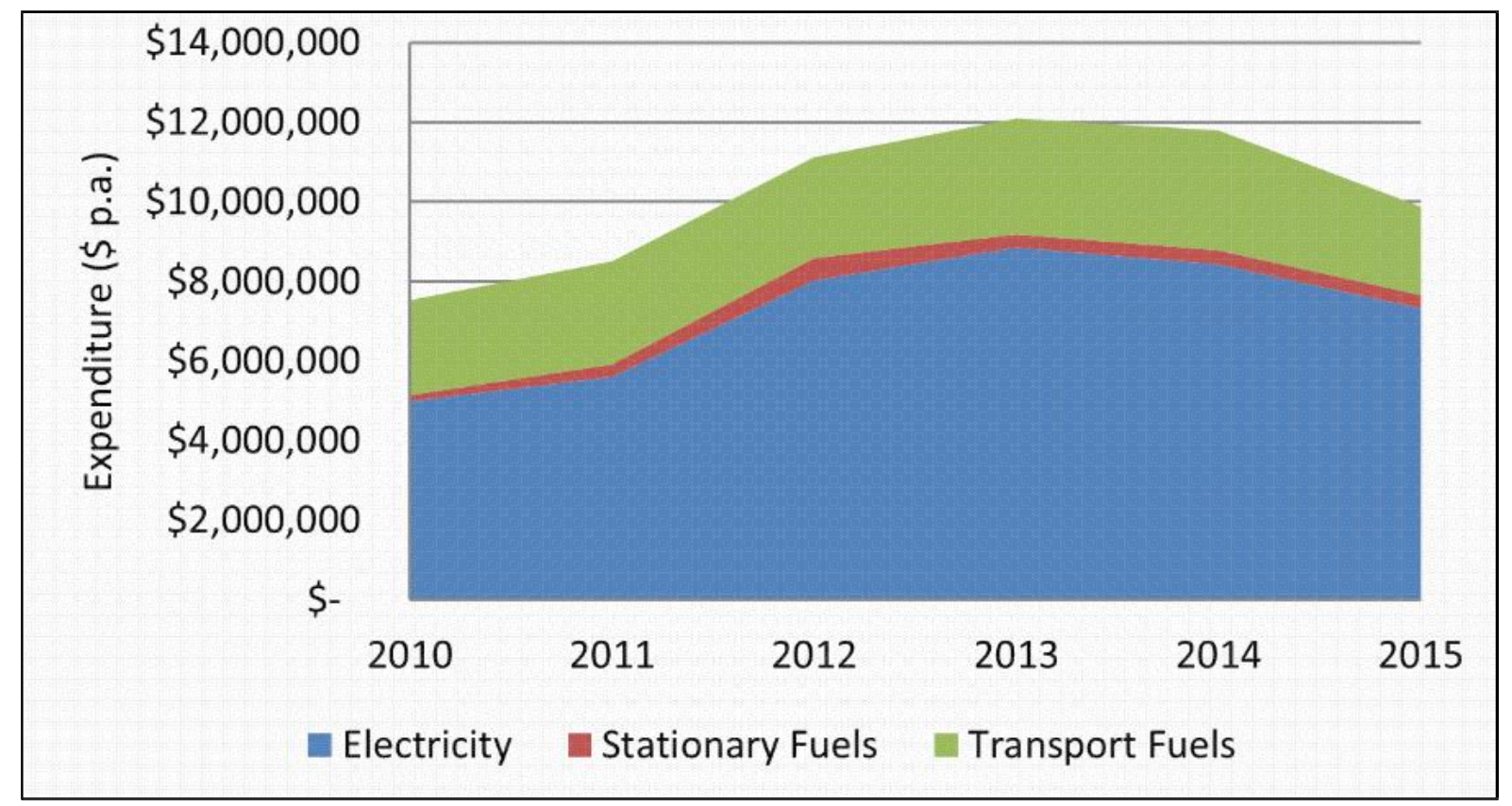

Figure 5 Gosford City Council nominal energy cost by source 


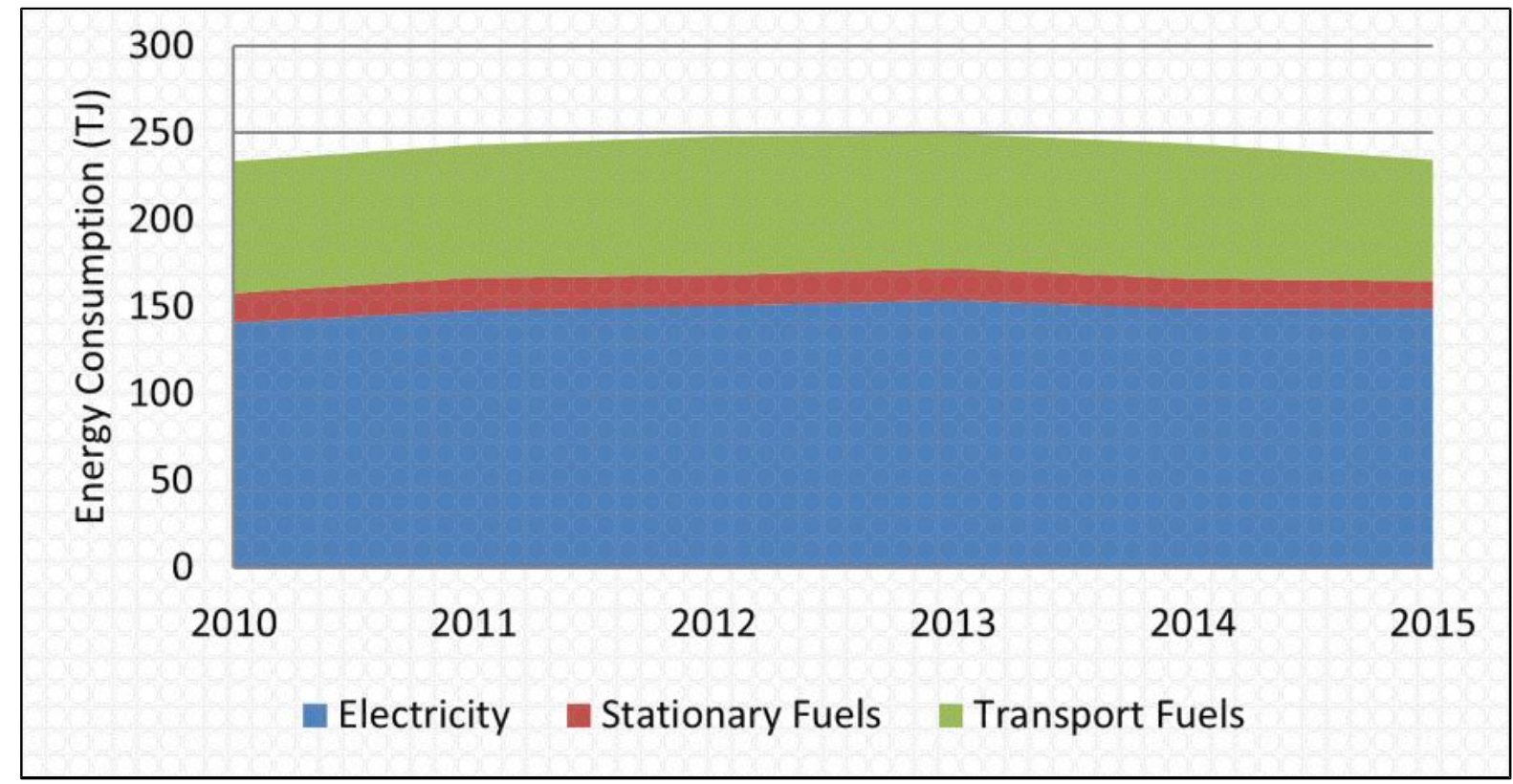

Figure 6 Gosford City Council energy consumption by source

\section{Energy Management Strategy (2015)}

Council is now building on the tactical carbon and energy management system improvements by developing an energy management strategy. The fundamental objective of the energy management strategy is to drive improvements in the energy productivity of Council's operations. This approach is different to previous approaches which were focused on using less and paying less. The main difference is the energy productivity approach recognises that using less energy is not necessarily the optimal outcome. The energy productivity lens is expected to uncover previously overlooked opportunities by recognising the total economic value associated with Council's energy use. This approach focuses on maximising the value Council generates from its energy use.

The energy strategy also introduces more advanced energy metrics such as asset class energy intensity metrics and an organisational energy index. The purposes of the asset class energy intensity metrics are to improve energy consumption benchmarking and identify high and low performing assets (Table 2). The energy intensity metrics have been used to develop an organisational energy index, designed to provide a high level indicator of Council's energy performance through time. The Gosford City Council energy index is the geometric mean of the energy intensity of each major asset class (Equation 1).

Equation 1
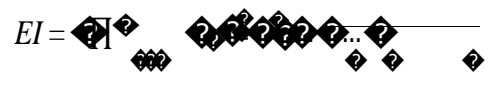

Where:

EI is energy index

$k$ is number of asset classes

$x_{n}$ is the energy intensity of each asset class

Table 2 Energy Intensity Metrics for key asset classes

\begin{tabular}{|c|c|c|c|}
\hline Asset Class & Asset sub class & Energy Intensity Metric & Units \\
\hline \multirow[t]{3}{*}{ Water } & Raw Water Pumping & Energy per unit of water supplied & $\mathrm{MJ} / \mathrm{ML}$ \\
\hline & Water Treatment & Energy per unit of water treated & $\mathrm{MJ} / \mathrm{ML}$ \\
\hline & Water Distribution & Energy per unit of water supplied & $\mathrm{MJ} / \mathrm{ML}$ \\
\hline \multirow[t]{2}{*}{ Sewerage } & Sewerage Collected & Energy per unit of wastewater collected & $\mathrm{MJ} / \mathrm{ML}$ \\
\hline & Sewerage Treated & Energy per unit of COD treated & $\mathrm{MJ} / \mathrm{kgCOD}$ \\
\hline \multirow[t]{2}{*}{ Buildings } & Actively Heated/Cooled & Energy per degree day square meter of floor area & MJ/DD.m2 \\
\hline & Passive Heating/Cooling & Energy per square meter of floor area & $\mathrm{MJ} / \mathrm{m} 2$ \\
\hline Lighting & $\begin{array}{l}\text { Street Lighting } \\
\text { Public Lighting } \\
\text { Sports Fields Lighting }\end{array}$ & Energy per square meter od light space & $\mathrm{MJ} / \mathrm{m} 2$ \\
\hline
\end{tabular}




\section{Energy Productivity}

Energy productivity is a fourth lens to add to the carbon emission, energy consumption and energy cost lenses. The energy productivity lens is expected to provide insights into the organisation's energy and carbon performance, driving improvements in Council's operational efficiency, manage its risks and ultimately improve the affordability of Council services for our community. Energy productivity aims to increase the total economic value the Council generates with the energy it uses. Put simply it aims to do more with the dollars Council spends on energy. Office lighting is a good example to highlight the benefits of factoring in productivity gains. Council assessed an energy saving opportunity to change office lights from tubular fluorescent (T5) to LED. The LEDs were estimated to provide marginal energy cost and maintenance cost reductions. However, the LED lights provide improved light quality. Romm \& Browning (1998) reported staff productivity gains from improved office energy efficiency of $15 \%$. Even if a $0.5 \%$ improvement in staff productivity was achieved the simple payback period was reduced from 20 years to less than 2 years. Factoring in productivity gains is expected to identify further energy saving opportunities for Council and the community.

\section{Conclusion}

Clearly the appropriate approach to energy and carbon management can evolve in line with wider organisation objectives and maturity of its energy and carbon management systems. Over the last fifteen years Gosford City Council has advanced the management of energy and carbon emissions from Council's operations. Council has transitioned from an aspirational carbon reduction program through an evidence based carbon reduction program, to managing energy and carbon emissions through to the latest inclusion of energy productivity. The shift towards focusing on financial benefits has resulted in more change with associated improved environmental benefits. The latest shift to include the consideration of energy productivity benefits is likely to result in more energy performance improvement projects by recognising the wider economic value of energy management initiatives. However, the risk is it will ignore carbon \& energy projects that would have large environmental benefits without financial or economic benefits.

Selecting the most appropriate approach to manage an organisation's energy use and carbon footprint should reflect the organisational values. Even with similar objectives the approach can significantly influence the success or failure of the energy and carbon management program.

\section{References}

Dowling D, Waters D L, Wu S and Hardisty P (2012) Gosford City Council Climate Change Mitigation Strategy: Commitment made to a carbon reduction target of 20 per cent by the year 2025. Water Nov. 2012, pp. $1-5$.

Romm J J \& Browning W D (1998) Greening the Building and the Bottom Line: Increasing Productivity Through Energy-Efficient Design, Rocky Mountain Institute, http://www.columbia.edu/cu/alliance/EDF-2012documents/Reading_Fox_3.pdf [accessed 27/11/2015]. 